6 Connolly SJ, Laupacis A, Gent M, Roberts RS, Cairns JA, Joyner C. Canadian atrial fibrillation anticoagulation (CAFA) study. J Am Coll Cardiol 1991;18:349-55

7 Stroke Prevention in Atrial Fibrillation Investigators. Warfarin versus aspirin for prevention of thromboembolism in atrial fibrillation: stroke prevention in atrial fibrillation II study. Lancet 1994:343:687-91.

8 Knottnerus JA. Medical decision making by general practitioners and specialists. Fam Pract 1991;8:305-7.

9 Stroke Prevention in Atrial Fibrillation Investigators. Patients with non-valvular atrial fibrillation at low risk of stroke during treatment with aspirin. JAMA 1998;279:1273-7.

10 Kopecky SL, Gersh BJ, McGoon MD, Whisnant JP, Holmes DR, Ilstrup DM, et al. The natural history of lone atrial fibrillation. $N$ Engl J Med 1987:317:669-74.

11 Zwietering P, Knottnerus A, Gorgels T, Rinkens P. Occurrence of arrhythmias in general practice. Scand J Prim Health Care 1996;14:244-50.

12 Langenberg M, Hellemons BSP, van Ree JW, Vermeer F, Lodder J, Schouten HJA, Knottnerus JA. Atrial fibrillation in elderly patients: prevalence and comorbidity in general practice. BMJ 1996;313:1534.

13 Meade TW, Roderick PJ, Brennan PJ, Wilkes HC, Kelleher CC. Extra-cranial bleeding and other symptoms due to low-dose aspirin and low-AC. Thromb Haemostas 1992:68:1-6.

14 Fihn SD, Callahan CM, Martin DC, McDonell MB, Henikoff JG, White $\mathrm{RH}$. The risk for and severity of bleeding complications in elderly patients treated with warfarin. Ann Intern Med 1996;124:970-9.

15 Landefeld CS, Goldman L. Major bleeding in outpatients treated with warfarin: incidence and prediction by factors known at the start of outpatient therapy. Am J Med 1989;87:144-52.

16 Hull R, Hirsch J, Jay R, Carter C, England C, Gent M, et al. Different intensity of oral anticoagulant therapy in treatment of proximal vein thrombosis. N Engl J Med 1982;307:1676-81.

17 Poller L, McKernan A, Thomson JM, Elstein M, Hirsch J, Jones JB. Fixed minidose warfarin: a new approach to prophylaxis against venous thrombosis after major surgery. BMJ 1987;295:1309-12.

18 Hellemons BSP, Langenberg M, Lodder J, Vermeer F, Schouten HJA, Lemmens ThGJ, et al. Primary prevention of arterial thromboembolism in non-rheumatic atrial fibrillaiotn: the PATAF trial study design. Control Clin Trials 1999'20:386-93.

19 Schouten HJA. Adaptive biased urn randomization in small strata when blinding is impossible. Biometrics 1995;51:1529-35.

20 Freedman LS. Tables of the number of patients required in clinical trials using the logrank test. Stat Med 1982;1:121-9.
21 The Stroke Prevention in Atrial Investigators. Predictors of thromboembolism in atrial fibrillation: I. Clinical features of patients at risk. Ann Intern Med 1992;116:1-5.

22 Snapinn SM. Monitoring clinical trials with a conditional probability stopping rule. Stat Med 1992;11:659-72.

23 Atrial Fibrillation Investigators. Risk factors for stroke and efficacy of antithrombotic therapy in atrial fibrillation. Arch Intern Med 1994;154:1449-57.

24 EAFT (European Atrial Fibrillation Trial) Study Group. Secondary prevention in non-rheumatic atrial fibrillation after transient ischaemic attack or minor stroke. Lancet 1993;342:1255-62.

25 Laupacis A, Albers G, Dalen J, Dunn M, Feinberg W, Jacobson A. Antithrombotic therapy in atrial fibrillation. Chest 1995;108:352-9S.

26 Feinberg WM, Blackshear JL, Laupacis A, Krinmal R, Hart RG. Prevalence, age distribution, and gender of patients with atrial fibrillation. Arch Intern Med 1995; 155:469-73.

27 Stroke Prevention in Atrial Fibrillation Investigators. Adjusted warfarin versus low-AC, fixed-dose warfarin plus aspirin for high risk patients with atrial fibrillation: stroke prevention in atrial fibrillation III randomized clinical trial. Lancet 1996;348:633-8.

28 Coumadin Aspirin Reinfarction Study (CARS) Investigators. Randomised double-blind trial of fixed low-dose warfarin with aspirin after myocardial infarction. Lancet 1997;350:389-96.

29 Antiplatelet Trialists' Collaboration. Collaborative overview of randomized trials of antiplatelet therapy. 1. Prevention of death, myocardial infarction, and stroke by prolonged antiplatelet therapy in various categories of patients. BMJ 1994;308:81-106.

30 Hart RG, Harrison MJG. Aspirin wars. The optimal dose of aspirin to prevent stroke. Stroke 1996;27:585-7.

31 Lip GYH. Thromboprophylaxis for atrial fibrillation. Lancet 1999; 353:4-6.

32 Rickles FR, Edwards RL. Activation of blood coagulation in cancer: Trousseau's syndrome revisited. Blood 1983;62:14-31.

33 Levine M, Hirsch J, Gent M, Arnold A, Warr D, Falanga A, et al. Doubleblind randomized trial of very-low-dose warfarin for prevention of thromboembolism in stage IV breast cancer. Lancet 1994;343:886-9.

34 Sudlow CM, Rodgers H, Kenny RA, Thomson RG. Service provision and use of anticoagulants in atrial fibrillation. BMJ 1995;311:558-61.

(Accepted 15 September 1999)

\title{
Pragmatic randomised controlled trial of local corticosteroid injection and naproxen for treatment of lateral epicondylitis of elbow in primary care
}

\author{
Elaine M Hay, Susan M Paterson, Martyn Lewis, Gillian Hosie, Peter Croft
}

Staffordshire

Rheumatology

Centre, The

Haywood, Burslem,

Stoke on Trent

ST6 7AG

Elaine M Hay

senior lecturer in

community

rheumatology

continued over

BMJ 1999;319:964-8

website

extra

A further table and members of the

the Community

Musculoskeletal

Research Group

are given on the

BMJ's website

www.bmj.com

\begin{abstract}
Objective To compare the clinical effectiveness of local corticosteroid injection, standard non-steroidal anti-inflammatory drugs, and simple analgesics for the early treatment of lateral epicondylitis in primary care. Design Multicentre pragmatic randomised controlled trial.

Setting 23 general practices in North Staffordshire and South Cheshire.

Participants 164 patients aged 18-70 years presenting with a new episode of lateral epicondylitis.

Interventions Local injection of $20 \mathrm{mg}$

methylprednisolone plus lignocaine, naproxen 500

$\mathrm{mg}$ twice daily for two weeks, or placebo tablets. All

participants received a standard advice sheet and

co-codamol as required.

Main outcome measures Participants' global assessment of improvement (five point scale) at four weeks. Pain, function, and "main complaint" measured on 10 point Likert scales at 4 weeks, 6 months, and 12 months.

Results Over 2 years, 53 subjects were randomised to injection, 53 to naproxen, and 58 to placebo. Prognostic variables were similar between groups at baseline. At 4 weeks, 48 patients (92\%) in the injection group were
\end{abstract}

completely better or improved compared with 30 $(57 \%)$ in the naproxen group $(\mathrm{P}<0.001)$ and $28(50 \%)$ in the placebo group $(\mathrm{P}<0.001)$. At 12 months, 43 patients (84\%) in the injection group had pain scores $\leqslant 3$ compared with $45(85 \%)$ in the naproxen group and $44(82 \%)$ in the placebo group ( $\mathrm{P}>0.05)$.

Conclusions Early local corticosteroid injection is effective for lateral epicondylitis. Outcome at one year was good in all groups, and effective early treatment does not seem to influence this.

\section{Introduction}

Lateral epicondylitis (tennis elbow) is a painful condition that affects about 4 adults per 1000 annually. ${ }^{1}$ Most cases are managed in primary care, and more than 40 possible treatments have been proposed, ${ }^{2}$ reflecting a lack of consensus about optimal management. General practitioners commonly use non-steroidal antiinflammatory drugs to treat tennis elbow, but there are no trials comparing them with painkillers and one study found no clinically important benefit over placebo. ${ }^{3}$ Two reviews of corticosteroid injections concluded that there was insufficient evidence to support their use in treating tennis elbow, but the methodological quality of most trials was poor. ${ }^{45}$ Only two primary care studies were 
identified, both with methodological shortcomings, including small sample sizes. One, in an occupational health centre, showed no difference between injection, indomethacin, and a wrist brace over 12 months. ${ }^{6}$ The second, conducted in an army clinic, found no difference between ultrasound, transcutaneous nerve stimulation, and local injection five days after intervention. ${ }^{7}$

We conducted a large pragmatic randomised trial comparing three conventional treatments for lateral epicondylitis in primary care. The aims of the study were to determine whether local corticosteroid injection, a two week course of naproxen, or simple analgesia provides the best short term treatment for new episodes and which of these treatments provides best long term relief of symptoms.

\section{Methods}

\section{Study design}

The study was a multicentre, pragmatic randomised trial in primary care. We recruited consecutive patients aged 18-70 years who consulted their general practitioner with a new episode of lateral epicondylitis (pain and tenderness in the lateral region of the elbow and no consultation with symptoms in the same elbow during the preceding 12 months) during November 1995 to December 1997. Exclusion criteria were a history of inflammatory arthritis or gross structural abnormality of the elbow; contraindications to non-steroidal antiinflammatories or local steroid injection; and pregnancy or breast feeding. The trial was explained to patients by their general practitioner, who gave participants an information leaflet and faxed a registration form to the research centre. Baseline assessments were performed by a study nurse (usually in the patients' homes) within two working days of registration. Written informed consent was obtained, and the study was approved by the local research ethics committees of North Staffordshire and South Cheshire.

\section{Randomisation}

Treatment allocation was according to the study number given to the patient at the baseline assessment. Numbers were issued in a predetermined random sequence in blocks of six by general practice and generated with a random number table. The number corresponded with that on identical treatment packs kept in the general practitioners' surgeries.

\section{Treatment protocols}

Patients returned to their general practitioner after the baseline assessment to receive one of three treatments.

Injection group-Patients were given a local corticosteroid injection of methylprednisolone $20 \mathrm{mg}$ and 0.5 $\mathrm{ml} 1 \%$ lignocaine according to a standard technique. The injection was performed with the patient's arm resting flexed on a firm surface. The methylprednisolone and lignocaine were drawn up in separate syringes. After the skin was cleaned, lignocaine was injected deep into the subcutaneous tissues and muscles $1 \mathrm{~cm}$ distal to the lateral epicondyle and aiming towards the tender spot. The syringes were then exchanged and methylprednisolone injected radially. The needle was withdrawn cleanly and firm pressure applied.

Naproxen group-Patients were prescribed enteric coated naproxen $500 \mathrm{mg}$ twice daily for two weeks.
Standard advice was given to take the drug with food and about potential side effects.

Placebo group-Patients were give placebo tablets (unmarked vitamin C) twice daily for two weeks. Standard advice was given as for the naproxen group.

Participants were provided with co-codamol for additional pain relief and an information leaflet about "tennis elbow" based on the Arthritis Research Campaign publication but omitting specific treatment recommendations.

\section{Outcome measures}

Outcome assessments were performed by a blinded study nurse before randomisation and at four weeks, six months, and 12 months. The baseline assessment also included demographic variables, medical history, and potential prognostic variables. Case notes were reviewed after completion of follow up.

The primary outcome was patients' global assessment of change measured on a 5 point scale (complete recovery, improved, no change, worse, much worse) at four weeks. Secondary outcomes were pain severity (10 point Likert scale); impairment of function (10 point Likert scale); severity of "main complaint" (10 point Likert scale) ${ }^{8}$; disability (validated tennis elbow disability questionnaire $)^{9}$; pain free grip strength in affected arm (average of two readings with hand held dynamometer); local tenderness of lateral epicondyle (3 point scale: none, some, definite with flinch); pain on resisted extension of middle finger and wrist with arm extended (3 point scale: none, some, definite with flinch); number and type of co-interventions (questionnaire and case note review); time off paid employment; complications of treatment (post-intervention exacerbation of pain (daily 10-point pain scale measured for five days), local skin atrophy, gastrointestinal side effects).

\section{Analysis}

Sample size calculations were based on publications which describe a 70\% recovery or improvement with non-steroidal anti-inflammatory drugs after four weeks (two tailed $\alpha=0.05, \beta=0.2$ ). ${ }^{10}$ Overall success was defined a priori as a $20 \%$ difference between treatment groups in the primary outcome measure. A total sample size of 180 patients was required.

Intention to treat analysis was performed blind to treatment group. All hypothesis tests were two tailed with $\alpha=0.05$. We compared groups with $\chi^{2}$ test for nominal variables or Fisher's exact test where appropriate for small samples. Ordinal variables were compared by Mann-Whitney U tests. Area under the curve slopes were compared by the methods of Matthews et al. ${ }^{11}$ Analyses were carried out with sPss version 8.0.

\section{Results}

Thirty seven general practitioners from 23 practices registered 182 patients. Of these patients, 164 (78 women) were randomised: 53 to receive local injection, 53 to naproxen, and 58 to placebo. Eleven of the 37 general practitioners recruited six or more patients, accounting for 94 (57\%) of the 164 in the study population (overall range recruited 1-17). Allocation of intervention and baseline patient characteristics were similar in high recruiting and low recruiting practices.
Primary Care Sciences Research Centre, Keele

University School of Postgraduate

Medicine, Hartshill, Stoke on Trent

ST4 7QB

Susan M Paterson research nurse

Martyn Lewis statistician

Peter Croft

professor of epidemiology

1980 Great Western Road, Glasgow G13 2SW

Gillian Hosie general practitioner

Correspondence to: E M Hay Pra19@keele.ac.uk 


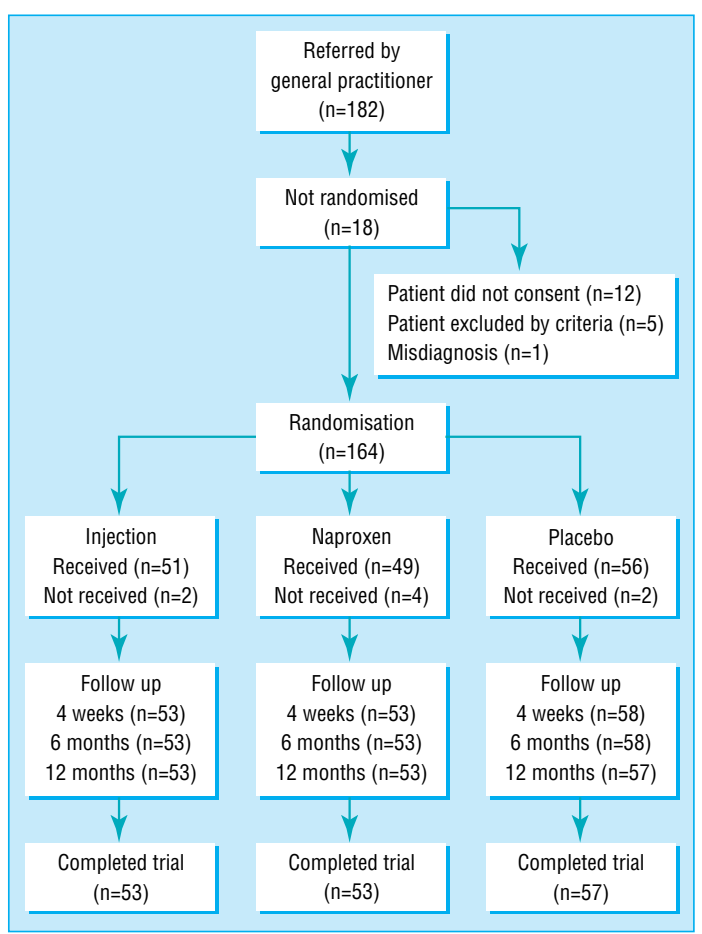

Patient recruitment, randomisation to treatment group, and follow up rates

The figure shows the progress of patients through the trial, and table 1 shows the baseline characteristics of the study sample.

At four weeks, outcome in the injection group was significantly better than in the naproxen and placebo groups (table 2). Naproxen showed no advantage over placebo. Recovery or improvement was reported in 48 patients (92\%) in the injection group, 30 patients (57\%) in the naproxen group, and 28 patients $(50 \%)$ in the placebo group.

Table 3 shows median scores for the Likert scales for pain, function, and "main complaint" at each follow up assessment. At four weeks, injection showed a clear advantage over naproxen and placebo. There were some small but significant differences in favour of naproxen or placebo at 6 and 12 months.

The clinical interpretation of these differences was explored as follows. Comparison between the Likert scores for pain and participants' global assessment of change at four weeks showed that $89 \%$ of subjects scoring $\leqslant 3$ rated themselves as completely better or improved; none had got worse. Based on this, outcome was dichotomised as "better" (pain score $\leqslant 3$ ) or "not better" (pain score $\geqslant 4$ ). This allowed us to compare the numbers of patients who had responded to treatment at each time point (table 4). Overall, $84 \%$ of recruited patients were better at 12 months, and this proportion was similar for each treatment group (injection $84 \%$, naproxen $85 \%$, placebo $82 \%$ ). Some subjects in the injection group, however, had worsened at six months but improved again by 12 months.

Details of the self reported presence of elbow pain, the nurse's examination findings, and disability scores are given on the $B M J$ s website. Injection was superior to naproxen and placebo at four weeks; the three groups were similar at 12 months with a relapse in some patients in the injection group at six months.
The numbers of patients taking time off paid employment at four weeks were five (14\%) in the injection group, four $(10 \%)$ in the naproxen group, and eight $(17 \%)$ in the placebo group; the numbers at 12 months were five (14\%), four (10\%), and $10(21 \%)$, respectively ( $\mathrm{P}>0.05$ for both times). The numbers of patients taking painkillers in each group at four weeks and six and 12 months were similar: 18 (35\%), 22 $(42 \%)$, and $29(50 \%)$ at four weeks; $21(40 \%), 19(36 \%)$, $23(40 \%)$ at six months, and 14 (26\%), 14 (26\%), and 16 $(28 \%)$ at 12 months for injection, naproxen, and placebo groups respectively.

\section{Co-interventions}

Case notes were available for 160 participants; four had transferred practices. In all, 155 records (50 injection, 52 naproxen, 53 placebo) had information about the randomised treatment, and 151 records (49 injection, 50 naproxen, 52 placebo) had complete information concerning patient treatment between the date of referral and follow up.

Numbers of co-interventions did not differ significantly between groups during follow up (table 5). A second injection was received by seven (14\%) patients in the injection group; 17 (34\%) patients in the naproxen group and $15(29 \%)$ in the placebo group

Table 1 Baseline characteristics of participants according to treatment group. Values are numbers (percentages) of participants $^{\star}$

\begin{tabular}{|c|c|c|c|}
\hline & $\begin{array}{c}\text { Injection } \\
(\mathrm{n}=53)\end{array}$ & $\begin{array}{c}\text { Naproxen } \\
(\mathrm{n}=53)\end{array}$ & $\begin{array}{c}\text { Placebo } \\
(\mathrm{n}=58)\end{array}$ \\
\hline \multicolumn{4}{|l|}{ Demography } \\
\hline Age ( $\geqslant 45$ years) & 37 (70) & $36(68)$ & $36(62)$ \\
\hline Sex (male) & $31(59)$ & $25(47)$ & $30(52)$ \\
\hline Social class (manual) & $27(66)$ & $22(51)$ & $28(57)$ \\
\hline \multicolumn{4}{|l|}{ Pain } \\
\hline Elbow pain today & $50(94)$ & $51(96)$ & $57(98)$ \\
\hline Pain every day for 1 week & $50(94)$ & $47(89)$ & $50(86)$ \\
\hline Duration of pain $>3$ months & $19(36)$ & $13(25)$ & $18(31)$ \\
\hline Both elbows affected & $7(13)$ & $4(8)$ & $4(7)$ \\
\hline Previous episode(s) & $10(19)$ & $11(21)$ & $11(19)$ \\
\hline Belief that current episode was activity induced & $30(57)$ & $25(47)$ & $30(52)$ \\
\hline \multicolumn{4}{|l|}{ Work } \\
\hline Employed & $38(72)$ & $38(72)$ & $48(83)$ \\
\hline Time off work & $6(16)$ & $0(0)$ & $7(15)$ \\
\hline \multicolumn{4}{|l|}{ General health } \\
\hline Long standing medical condition & $25(47)$ & $24(45)$ & $18(31)$ \\
\hline Medication or pain killers in past 48 hours & $41(77)$ & $36(68)$ & $41(71)$ \\
\hline \multicolumn{4}{|l|}{ Appearance } \\
\hline Superficially normal joint & $49(93)$ & $49(93)$ & $55(95)$ \\
\hline Skin atrophy present & $0(0)$ & $0(0)$ & $0(0)$ \\
\hline \multicolumn{4}{|l|}{ Movement and strength } \\
\hline Grip strength >300 mm Hg & $3(6)$ & $1(2)$ & $1(2)$ \\
\hline $\begin{array}{l}\text { Definite pain on resisted extension of middle } \\
\text { finger }\end{array}$ & $18(34)$ & $24(45)$ & $20(35)$ \\
\hline Definite pain on resisted extension of wrist & $22(42)$ & $25(47)$ & $28(48)$ \\
\hline Definite tenderness & $23(43)$ & $15(28)$ & $24(41)$ \\
\hline \multicolumn{4}{|l|}{ Disability } \\
\hline Dressing & $32(63)$ & $29(55)$ & $31(57)$ \\
\hline Feeding & $41(79)$ & $44(85)$ & $42(72)$ \\
\hline Washing & $38(76)$ & $41(77)$ & $45(80)$ \\
\hline Household tasks & $50(94)$ & $49(93)$ & $55(95)$ \\
\hline Opening doors & $24(47)$ & $24(48)$ & $26(47)$ \\
\hline Carrying objects & $51(96)$ & $49(93)$ & $57(98)$ \\
\hline With work & $46(90)$ & $47(90)$ & $52(91)$ \\
\hline With sport & $36(77)$ & $35(85)$ & $42(82)$ \\
\hline
\end{tabular}

*Percentages may not calculate exactly because of missing data. 
also received an injection during follow up. Fewer patients in the injection group reconsulted their general practitioner within four weeks of the randomised intervention, but observed consultation for tennis elbow pain was similar in all three groups by 12 months.

\section{Side effects}

Local skin atrophy at the lateral epicondyle was observed in only two patients at six months and one patient at 12 months. The three affected patients were from the naproxen and placebo groups, and only one had additionally received a local injection. Naproxen was discontinued in four patients because of gastrointestinal side effects. One patient on naproxen had an allergic reaction characterised by oedema. Pain diaries recorded for five days after intervention showed a minor, non-significant, increase in severity of pain after injection, lasting one day only.

\section{Discussion}

Our results have two important implications for the management of new episodes of lateral epicondylitis in general practice. Firstly, a local corticosteroid injection is an effective, safe initial treatment with a clear clinical advantage four weeks later compared with a two week course of naproxen. Naproxen had no advantage over simple analgesics and a standard advice sheet alone. Secondly, by 12 months most patients with lateral epicondylitis had improved irrespective of initial treatment. Early effective treatment with local steroid injection resulted in more rapid resolution of symptoms but did not influence long term outcome.

A small proportion of patients failed to respond to the initial injection, and some patients who had initially improved had worse symptoms at six months. These may be patients whose primary disease lay within the

Table 4 Numbers (percentages) of patients with lateral epicondylitis who were better (pain score $\leqslant 3$ ) at follow up compared with baseline according to treatment group*

\begin{tabular}{lccc} 
Follow up & Injection $(\mathbf{n}=\mathbf{5 3})$ & Naproxen $(\mathbf{n}=\mathbf{5 3})$ & Placebo $(\mathbf{n}=\mathbf{5 8})$ \\
\hline 4 weekst & $41(82)$ & $25(48)$ & $28(50)$ \\
\hline 6 months $\ddagger$ & $33(65)$ & $42(81)$ & $47(83)$ \\
\hline 12 months & $43(84)$ & $45(85)$ & $44(82)$ \\
\hline
\end{tabular}

*Percentages may not calculate exactly because of missing data. $\dagger \mathrm{P}<0.05$ for injection versus naproxen.

$\ddagger \mathrm{P}<0.05$ for injection versus placebo.

Table 5 Numbers (percentages) of patients recorded to have reconsulted with general practitioner and received cointerventions during follow up*

\begin{tabular}{lccc} 
& $\begin{array}{c}\text { Injection } \\
(\mathbf{n}=\mathbf{5 3})\end{array}$ & $\begin{array}{c}\text { Naproxen } \\
(\mathbf{n}=\mathbf{5 3})\end{array}$ & $\begin{array}{c}\text { Placebo } \\
(\mathbf{n}=\mathbf{5 8})\end{array}$ \\
\hline Reconsultation & $9(18)$ & $16(32)$ & $12(23)$ \\
\hline 4 weeks & $20(41)$ & $24(48)$ & $21(40)$ \\
\hline 6 months & $25(51)$ & $24(48)$ & $22(42)$ \\
\hline 12 months & & & \\
\hline Cointerventions & $6(12)$ & $9(18)$ & $10(19)$ \\
\hline 4 weeks & $13(27)$ & $18(36)$ & $18(35)$ \\
\hline 6 months & $17(35)$ & $19(38)$ & $19(37)$ \\
\hline
\end{tabular}

${ }^{*}$ Numbers are cumulative totals during follow up. Percentages may not calculate exactly because of missing data.
Table 2 Outcome at four weeks after invention according to treatment group. Values are numbers (percentages) of patients

\begin{tabular}{lcccc} 
Change in elbow & Injection* $(\mathbf{n}=\mathbf{5 2})$ & Naproxen $(\mathbf{n}=\mathbf{5 3})$ & Placebo $(\mathbf{n}=\mathbf{5 6})$ & Total $(\mathbf{n}=\mathbf{1 6 1})$ \\
\hline Complete recovery & $22(42)$ & $3(6)$ & $2(4)$ & $27(17)$ \\
\hline Some improvement & $26(50)$ & $27(51)$ & $26(46)$ & $79(49)$ \\
\hline No change & $3(6)$ & $16(30)$ & $23(41)$ & $42(26)$ \\
\hline Worse & $1(2)$ & $7(13)$ & $4(7)$ & $12(7)$ \\
\hline Much worse & $0(0)$ & $0(0)$ & $1(2)$ & $1(1)$ \\
\hline
\end{tabular}

${ }^{*} \mathrm{P}<0.05$ compared with naproxen and with placebo.

Table 3 Median (interquartile range) pain and disability self assessment scores (Likert scale 0-9) in patients with lateral epicondylitis according to treatment group

\begin{tabular}{|c|c|c|c|}
\hline Time of assessment & Injection & Naproxen & Placebo \\
\hline \multicolumn{4}{|l|}{ Elbow pain } \\
\hline Baseline & $6.0(4.0-7.0)$ & $4.0(2.75-6.25)$ & $5.0(4.0-7.0)$ \\
\hline 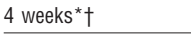 & $1.0(0.0-3.0)$ & $4.0(2.0-6.0)$ & $3.5(2.0-6.0)$ \\
\hline 6 months $^{*} \dagger$ & $2.0(1.0-5.0)$ & $1.0(0.0-3.0)$ & $1.0(0.0-2.25)$ \\
\hline 12 months & $1.0(0.0-2.0)$ & $0.0(0.0-2.0)$ & $0.0(0.0-2.0)$ \\
\hline Total scoreł & 221 (158-351) & $201(131-312)$ & 188 (138-277) \\
\hline \multicolumn{4}{|l|}{ Function } \\
\hline Baseline & $4.0(2.0-5.0)$ & $4.0(2.0-5.0)$ & $4.0(2.0-5.0)$ \\
\hline 4 weeks $^{*} \dagger$ & $0.0(0.0-2.0)$ & $3.0(1.0-5.0)$ & $2.0(1.0-4.0)$ \\
\hline 6 months $^{*}$ & $1.0(0.0-3.0)$ & $0.0(0.0-2.75)$ & $0.5(0.0-2.75)$ \\
\hline 12 months $†$ & $0.0(0.0-2.0)$ & $0.0(0.0-1.0)$ & $0.0(0.0-0.0)$ \\
\hline Total scoreł & $153(91-234)$ & $157(99-257)$ & 139 (106-227) \\
\hline \multicolumn{4}{|l|}{ Main complaint } \\
\hline Baseline & $6.0(4.0-7.0)$ & $5.0(4.0-7.0)$ & $5.5(3.0-7.0)$ \\
\hline 4 weeks $^{*} \dagger$ & $1.0(0.0-2.0)$ & $4.0(1.0-6.0)$ & $3.0(1.0-5.0)$ \\
\hline 6 months $^{*}$ & $2.0(0.0-4.0)$ & $0.0(0.0-3.0)$ & $1.0(0.0-4.0)$ \\
\hline 12 months $^{*}$ & $1.0(0.0-3.75)$ & $0.0(0.0-1.25)$ & $1.0(0.0-3.75)$ \\
\hline Total score $\ddagger$ & $222(129-340)$ & $180(116-275)$ & $195(141-361)$ \\
\hline
\end{tabular}

${ }^{*} \mathrm{P}<0.05$ for injection versus naproxen.

$\dagger P<0.05$ for injection versus placebo.

$\ddagger$ By area under the curve analysis.

cervical spine or whose local injection was not accurately placed. We did not give participants specific instructions about resting or abstaining from work or sporting activities, and effective pain relief might have led to a premature return to activity in the injection group causing a temporary worsening of their symptoms. Studies of other painful musculoskeletal syndromes, such as low back pain, ${ }^{12}$ have observed similar lack of association between early response to treatment and longer term outcomes. Further research is required to investigate these issues.

\section{Strengths and weaknesses}

The main criticism of previous reviews of treatment for tennis elbow has been the lack of methodologically rigorous trials. ${ }^{45}$ Our pragmatic study, carried out in a routine primary care setting, included a relatively homogeneous population of patients and was sufficiently large to detect clinically important differences between treatment groups. Possible prognostic variables were equally distributed between the three treatment groups at baseline. Although patients and doctors knew which treatment was given, the nurse who assessed outcome remained unaware of the treatment allocation throughout. Home based assessment minimised loss to follow up, enabling us to perform a robust intention to treat analysis.

We recognise a number of limitations to our study. Firstly, although we aimed to enrol all eligible patients consulting their general practitioner with a new episode of tennis elbow during the recruitment period, 
the variability in numbers of patients recruited by each general practitioner suggests that some potential participants were lost at this point. In some of the large group practices only one or two partners participated. We do not, therefore, have an accurate knowledge of the denominator population, making it difficult to use incidence of tennis elbow in primary care ${ }^{1}$ to estimate the proportion of all eligible subjects who were included in the study. However, there were no differences in participants' baseline characteristics between high and low recruiting practices, suggesting a lack of significant selection bias. By contrast, results from hospital based studies are difficult to generalise to primary care. ${ }^{35}$ Patients recruited in secondary care represent an unknown selection of all affected individuals seen by general practitioners and probably have more severe, persistent complaints. The median duration of disease in our patients (nine weeks) was shorter than in hospital based studies. ${ }^{41}$ This indicates that our study population consisted mainly of patients with relatively short duration of symptoms, characteristic of those seen in primary care.

Secondly, although standard treatment types and doses were used, our results apply only to the specific injection and non-steroidal anti-inflammatory regimens that we used. A two week course of a non-steroidal drug was chosen by the general practitioners as being in line with current prescribing practice for a self limiting condition and is the regimen most commonly used in other studies of this condition. ${ }^{10}$ Thirdly, general practitioners taking part in this study all had previous experience of injecting, ${ }^{13}$ and care was taken to standardise the injection procedure. Practitioners less skilled in administering soft tissue injections might not reproduce the positive results obtained in this study. However, the general practitioners were not intensively trained, their technique was not reviewed, and they were "service" general practitioners not members of specialist rheumatology groups or from designated research practices.

Time constraints in primary care make large scale trials like ours difficult to perform in the context of every day practice. We involved the general practitioners in designing the trial from an early stage to maximise ownership and commitment. ${ }^{14}$ The protocol was easy to follow, and use of a research nurse relieved general practitioners from as much of the paperwork and data recording as possible. Results from the study have been fed back to the general practitioners by post and in practice based workshops. This network of general practitioners is currently participating in further practice based intervention studies of common musculoskeletal conditions.

\section{Conclusions}

We conclude that corticosteroid injections are the initial treatment of choice for lateral epicondylitis in primary care if the objective of treatment is to obtain optimal relief of symptoms during the early weeks. Patients, however, can be reassured that regardless of their treatment the probability is high that they will get better in the longer term. Further research should determine why some patients do less well after initial pain relief by injection.
- Most lateral epicondylitis is managed by general practitioners, but optimum treatment is unclear

- This large pragmatic randomised trial showed that corticosteroid injection was significantly better than non-steroidal anti-inflammatories or placebo tablets at four weeks

- A two week course of a standard non-steroidal anti-inflammatory was no better than placebo

- A few patients who respond well initially to injection relapse by six months.

- Long term outcome was good, irrespective of initial treatment allocation

We thank the general practitioners from the Community Musculoskeletal Research Group (see $B M$ /s s website for list of names) for their enthusiasm and hard work. We thank the Primary Care Rheumatology Society, Professor A Silman, and Dr P Brennan for help with the study design and early encouragement and endorsement; Gill Latham for providing holiday cover for the study nurse; and Bronwyn Montgomory for preparing the treatment packages. Finally we thank the patients who made this project possible.

Contributors: EMH reviewed the literature, prepared the grant application, contributed to the design of the study, coordinated the study, contributed to the analysis, and acts as guarantor. SMP contributed to the literature review, designed the questionnaires, performed the patient interviews, contributed to coordination of the study, and performed most of the data entry. ML had the main responsibility for data analysis and contributed to the design and running of the study. GH contributed to the design of the study. PC contributed to the design and coordination of the study and supervised the data analysis. EMH wrote the manuscript, and tables and figures were prepared by ML. Various drafts were reviewed and revised by all the authors.

Funding: Arthritis Research Campaign. Methylprednisolone injections were provided by UpJohn and enteric coated naproxen by Syntex.

Competing interests: None declared.

1 Hamilton PG. The prevalence of humeral epicondylitis: a survey in general practice. J R Coll Gen Pract 1986;36:464-5.

2 Chard MD, Hazleman BL. Tennis elbow - a reappraisal. Br J Rheumatol 1989;28:186-90.

3 Labelle H, Guibert R. Efficacy of diclofenac in lateral epicondylitis of the elbow also treated with immobilization. University of Montreal Orthopaedic Research Group. Arch Fam Med 1997;6:257-62.

4 Labelle H, Guibert R, Joncas J, Newman N, Fallaha M, Rivard CH. Lack of scientific evidence for the treatment of lateral epicondylitis of the elbow. scientific evidence for the treatment of lateral epicondylitis of the elbow
An attempted meta-analysis. J Bone Joint Surg [Br] 1992;74B:646-51.

5 Assendelft WJ, Hay EM, Adshead R, Bouter LM. Corticosteroid injections for lateral epicondylitis: a systematic overview. Br J Gen Pract 1996;46:209-16.

6 Kivi P. The etiology and conservative treatment of humeral epicondylitis. Scand J Rehabil Med 1983;15:37-41.

7 Halle JS, Franklin RJ, Karalfa BL. Comparison of four treatment approaches for lateral epicondylitis of the elbow.J Orthop Sports Phys Ther 1986;8:62-9.

8 Beurskens AJ, de Vet HC, Lindeman E, Koke AJ, Regtop W, van der Hiejden GJ, et al. Efficacy of traction for non-specific low back pain: 5 week results of a randomised controlled trial. Lancet 1995;346:1596-600.

9 Stratford P, Levy DR, Gauldie S, Levy K, Miseferi D. Extensor carpi radialis tendonitis: a validation of selected outcome measures. Physiotherapy Canada 1987;39:250-5.

10 Stull PA, Jokl P. Comparison of diflusinal and naproxen in the treatment of tennis elbow. Clin Ther 1986;9:62-6.

11 Matthews JN, Altman DG, Campbell MJ, Royston P. Analysis of serial measurements in medical research. BMJ 1990;300:230-5.

12 Mitchell RI, Carmen GM. Results of a multicenter trial using an intensive active exercise programme for the treatment of acute soft tissue and back injuries. Spine 1990;15:514-21.

13 Lanyon P, Pope D, Croft P. Rheumatology education and management skills in general practice: a national study of trainees. Ann Rheum Dis 1995;54:735-9.

14 Foy R, Parry J, McAvoy B. Clinical trials in primary care: targeted payments for trials might help improve recruitment and quality. BMJ 1998;317:1168-9.

(Accepted 29 July 1999) 